\title{
'N ERGONOMIESE ONDERSOEK NA DIE PERSEPTUELE ONTWERPIMPLIKASIES VAN VURKHYSERHANTERING*
}

\author{
C.J.H. BLIGNAUT \\ DEPARTEMENT BEDRYFSIELKUNDE \\ RANDSE AFRIKAANSE UNIVERSITEIT
}

\begin{abstract}
The visual perception task is allocated to the operator component in the operator-forklift truck system. In this study the ability of operators to comply with the demands on depth perception imposed by the present design of forklift trucks was examined. The results of the study show that error occurrences differentiate significantly between operators in activities requiring depth perception, and that a larger visual angle significantly increases the number of errors in the vertical positioning of the forks. The results of the study are discussed in terms of design implications.
\end{abstract}

Een primêre oogmerk in die Ergonomika is om ontwerpbeslissings aangaande die fisiese aspekte van die mens se werksituasie in terme van die mens se sielkundige, fisiologiese, antropometriese en sosiale eienskappe te beïnvloed. Wanneer die mensmasjienstelsel as ontwerpobjek uitgesonder word, vervul die ergonoom sy beïnvloedingsrol veral gedurende die prosesse van funksietoekenning en raakvlakontwerp.

Funksietoekenning impliseer dat die funksies wat deur die stelsel ter bereiking van sy doel uitgevoer moet word, geïdentifiseer word en dat die funksies aan óf die mens- óf die masjienkomponente van die stelsel opgedra word. Ofskoon eksterne oorwegings soos die beskikbaarheid van arbeid, politieke en maatskaplike faktore 'n bepaalde invloed op die toekenning van funksies kan uitoefen, is die ergonoom in die laaste instansie steeds daaroor begaan of die funksies wat aan die mens toegewys word, nie slegs binne sy vermoënsgrense val nie, maar ook 'n geïntegreerde en betekenisvolle taak tot gevolg het. Vanuit 'n stelselontwikkelingsperspektief suggereer funksietoekenning 'n sekere finaliteit en daarmee saam gaan 'n gewigtige verantwoordelikheid, omdat daar kwalik in latere ontwikkelingsfases van

\footnotetext{
* Versoeke vir afdrukke moet aan die skrywer gerig word.
} 
dieselfde stelselgenerasie op vroeëre besluite teruggegaan kan word. Verfyning in opeenvolgende generasies van 'n stelsel, vanweë toenemende kennis, insig en tegnologiese sofistikasie is egter gewoonlik die reël.

Raakvlakontwerp weer het te doen met die integrering van die mens en die masjien in die sin dat sodanige verhouding tussen die mens en die masjien tot stand gebring word dat "die ontwerp van die een en die vaardighede van die ander" (Singleton, 1977, p. 293) optimale inligtingsvloei tot gevolg het. Betreffende ontwerpveranderlikes is die aard van vertoonmeganismes en kontroleapparaat, sowel as die rangskikking daarvan hier ter sprake. Die rasionaal onderliggend aan raakvlakontwerp is dat vertoon en kontrolemeganismes verlengstukke van die mens se waarnemings en responsievermoëns is en as sodanig verenigbaar met sy sielkundige, fisiologiese en antropometriese eienskappe behoort te wees.

In hierdie studie is daar getrag om die implikasies van funksieverdeling en in 'n mindere mate ook van raakvlakontwerp by vurkhysers na te gaan. Fox (1971) is van mening dat ofskoon die mens se biomeganiese beperkinge met die ontwerp van die vurkhyser oorkom is, is sy fisiese dilemma van materiaalhantering met subtieler sielkundige en fisiologiese probleme vervang. Hy wys verder daarop dat inligting voortspruitend uit ergonomiese navorsing aangaande die eise wat daar aan vurkhyseroperateurs gestel word, uiters beperk is. Hy stel dit só (a.w. p.3): "Semi-confidential reports of work by an American design consultant and veiled hints in the promotion material of one manufacturer seem to comprise the available data". Van die probleme wat Fox in verband met vurkhyserontwerp isoleer, hou verband met die gebrek aan standaardisasie ten opsigte van die uitleg, beweegrigting, hefboomkrag en die aard en voorkoms van vurkhyserkontrolemeganismes. Hierdie faktore kan tot foutiewe oordrag, foutiewe blinde reiking, die toepassing van oormatige krag en onnodige lang reikingsaksies lei. Fox wys ook daarop dat die hitte, geraas en vibrasie eie aan die konvensionele vurkhyser ergonomiese aandag regverdig vanweë die verband tussen faktore soos hierdie en lae rugpyn, fisiese vermoeidheid en toenames in ongeluksvatbaarheid.

Van pertinente belang vir hierdie studie is egter die sorg waarmee die waarnemingseise van die vurkhyseroperateur deur ergonome bejeën word. In die verband word daar in Mechanical Handling (Anoniem, 1976) op gewys dat die veilige funksionering van die mensvurkhyserstelsel steeds belemmer word deur die beperkings wat die vurkhysermas op die sig van die operateur plaas. In die artikel word 'n fotografiese en beligtingsmetode beskryf wat gebruik kan word in die evaluering van die onbelemmerde visuele veld van vurkhyseroperateurs. 
Drury en Dawson (1974) het in hulle studie van die standpunt uitgegaan dat die doeltreffendheid van materiaalhanteringstelsels nie soseer deur die vurkhyserkomponent nie, maar wel deur die operateurskomponent beperk word vanweë dié se onvermoë om die masjien te hanteer. Hulle toon dat foutvoorkoms en hanteringstyd 'n funksie van laterale speling in 'n "gang-deurry" taak en van teikengroot in 'n "langsnee-stop" taak is. Hulle bevindinge hou belangrike implikasies vir bergingsdigtheid, waardeur pakhuisuitleg en vurkhyserhantering beïnvloed word, in.

Die effek van dieptewaarneming op die taak om 'n vorentoe bewegende vurkhyser met sy vurk op 'n gegewe punt tot stilstand te bring (die sogenaamde langsnee-stop taak) is verder deur Drury, Cardwell en Easterby (1974) ondersoek. Hulle vind in 'n simulasie-eksperiment dat die grootte van die visuele hoek tussen die operateur se rigting van beweging en sy waarnemingslyn na die teikenpunt 'n invloed op operateursprestasie het. Hulle demonstreer dat prestasietyd en foute merkbaar toeneem indien die visuele hoek kleiner as 12 grade is en vind dat die aanvulling van visuele stimuli met behulp van geslotebaan televisie operateursprestasie drasties kan verbeter.

In hierdie studie is die kwessie van dieptewaarneming as dominante faktor in effektiewe vurkhyserhantering verder ondersoek. Dieptewaarneming wat met die finale posisionering van die vurkhyser oor 'n langsnee-dimensie verband hou (horisontale posisionering van die vurkhyser), en die soort dieptewaarneming wat nodig is vir die vertikale posisionering van die vurkhyser se vurke is by die huidige ondersoek ingesluit. Meer spesifiek was die studie daarop gemik om:

- $\quad$ te bepaal of verskille tussen vurkhyseroperateurs in terme van dieptewaarnemingsaktiwiteite verklaar kan word

- te bepaal of die grootte van die visuele hoek by die vertikale posisionering van die vurkhyser se vurke verband hou met die voorkoms van foute

- $\quad$ die mening van operateurs ten opsigte van vurkhysertake en vurkhyserontwerp te peil.

Hiermee wou daar vasgestel word of daar gronde bestaan vir 'n herevaluering van die wyse waarop dieptewaarnemingsfunksies aan die operateur van die vurkhyser toegeken word. 


\section{Dataversamelingstegnieke}

Die data waarop die studie berus is met behulp van onderstaande tegnieke, in die volgorde waarin dit uiteengesit is, versamel.

In die eerste plek is daar van 'n aktiwiteitsontleding gebruik gemaak. Die taak van die operateur-vurkhyserstelsel om 'n vrag op te lig is hiervoor uitgesonder. In hierdie taak is die volgende aktiwiteite geïdentifiseer: die nadering tot die vrag (dit is dieselfde as die langsneestop taak), die verstelling van die hellingshoek van die vurkhysermas, die vertikale posisionering van die vurke en die horisontale posisionering van die vurkhyser (in die beweegrigting van die vurkhyser). Slegs laasgenoemde twee aktiwiteite is in die studie ontleed vir die vrag op palette wat 1,30 meter (ooghoogte) en 2,6 meter (hoër hoogte) van die grond gestapel is en van hierdie hoogtes af opgelig moes word. Die aantal verstellings wat gedurende twintig vertikale en horisontale posisioneringsaktiwiteite uitgevoer word, sowel as stampe aan die vrag en spasies tussen die vrag en die rug van die vurke is aangeteken. In die ontleding van die aktiwiteitsdata is elke verstelling wat addisioneel tot die eerste gemaak is, sowel as elke stamp en spasie as 'n operateursfout beskou.

In die tweede plek is die menings en ervaringe van vurkhyseroperateurs met behulp van 'n gestruktureerde vraelys versamel. In die eerste gedeelte van die vraelys is die operateurs versoek om 'n aantal vurkhysertake, in terme van moeilikheidsgraad in rangorde te plaas. In die tweede gedeelte van die vraelys is die operateurs versoek om 'n aantal ontwerpveranderinge aan die vurkhyser, in terme van gewenstheid op 'n vierpuntskaal (van 1 ongewens tot 4 baie gewens) te beoordeel.

In die derde plek is die persone wat in 'n toesighoudende hoedanigheid met die vurkhyseroperateurs skakel, versoek om die operateurs in rangorde te plaas op grond van hul vaardigheid in die hantering van die vurkhyser.

\section{Die vurkhyseroperateurs}

Ten einde die effek van ongewenste, moeilik kontroleerbare veranderlikes uit te skakel is die studie in een onderneming uitgevoer. Die aktiwiteitsontleding en toesighouerbeoordelings is ten opsigte van die opligtaak normaalweg dieselfde soort vrag met dieselfde soort vurkhyser hanteer. Hierdie groep sowel as 12 ander operateurs in dieselfde onderneming wat andersoortige vrag hanteer, is versoek om die gestruktureerde vraelys te voltooi. 
Die vurkhyseroperateurs is op grond van die toesighouerbeoordelings in twee groepe verdeel. Die rangordes van die verskillende toesighouers het betekenisvol ooreengekom, $W(13)=, 75, \mathrm{p}<, 01$. Die resultate van die aktiwiteitsontleding is met behulp van ' $\mathrm{n}$ drierigting variansie-analise vir herhaalde waarnemings verder ondersoek. Statisties beduidende verskille is ten opsigte van die twee groepe operateurs sowel as die twee hoogtes waarop die vurke ingestel moes word, gevind. 'n Opsomming van die resultate van die variansie-analise word in Tabel 1 gegee terwyl die bevindinge grafies in Figuur 1 geïllustreer word.

\section{$\underline{\text { TABEL } 1}$}

\section{VARIANSIE-ANALISE VAN FOUTVOORKOMS BY DIE TWEE GROEPE OPERATEURS}

\begin{tabular}{|l|c|c|c|c|}
\hline Bron & $\begin{array}{c}\text { Som van } \\
\text { vierkante }\end{array}$ & $\begin{array}{c}\text { Grade van } \\
\text { vryheid }\end{array}$ & $\begin{array}{c}\text { Gemiddelde } \\
\text { Kwadraat }\end{array}$ & F-waarde \\
\hline Groepe (A) & 772,57 & 1 & 772,57 & $10,03 *$ \\
Dimensie (B) & 14 & 1 & 14 & 1,09 \\
Hoogte (C) & 578,57 & 1 & 578,57 & $24,90 *$ \\
Tussen pp & 1708,72 & 13 & & \\
pp tussen groepe & 936,15 & 12 & 77,01 & \\
Binne pp & 1577 & 42 & 12,73 & \\
Bxpp binne groepe & 152,86 & 12 & 23,23 & \\
Cxpp binne groepe & 278,78 & 12 & 39,49 & \\
BCxpp binne groepe & 473,93 & 12 & 41,14 & 3,23 \\
AB & 41,14 & 1 & 1,15 & 0,04 \\
AC & 1,15 & 1 & 18,29 & 0,46 \\
BC & 18,29 & 1 & 18,28 & \\
ABC & 18,28 & 1 & & \\
TOTAAL & 3285,72 & & & \\
$*$ p < 01 & & & & \\
& & & & \\
\hline
\end{tabular}




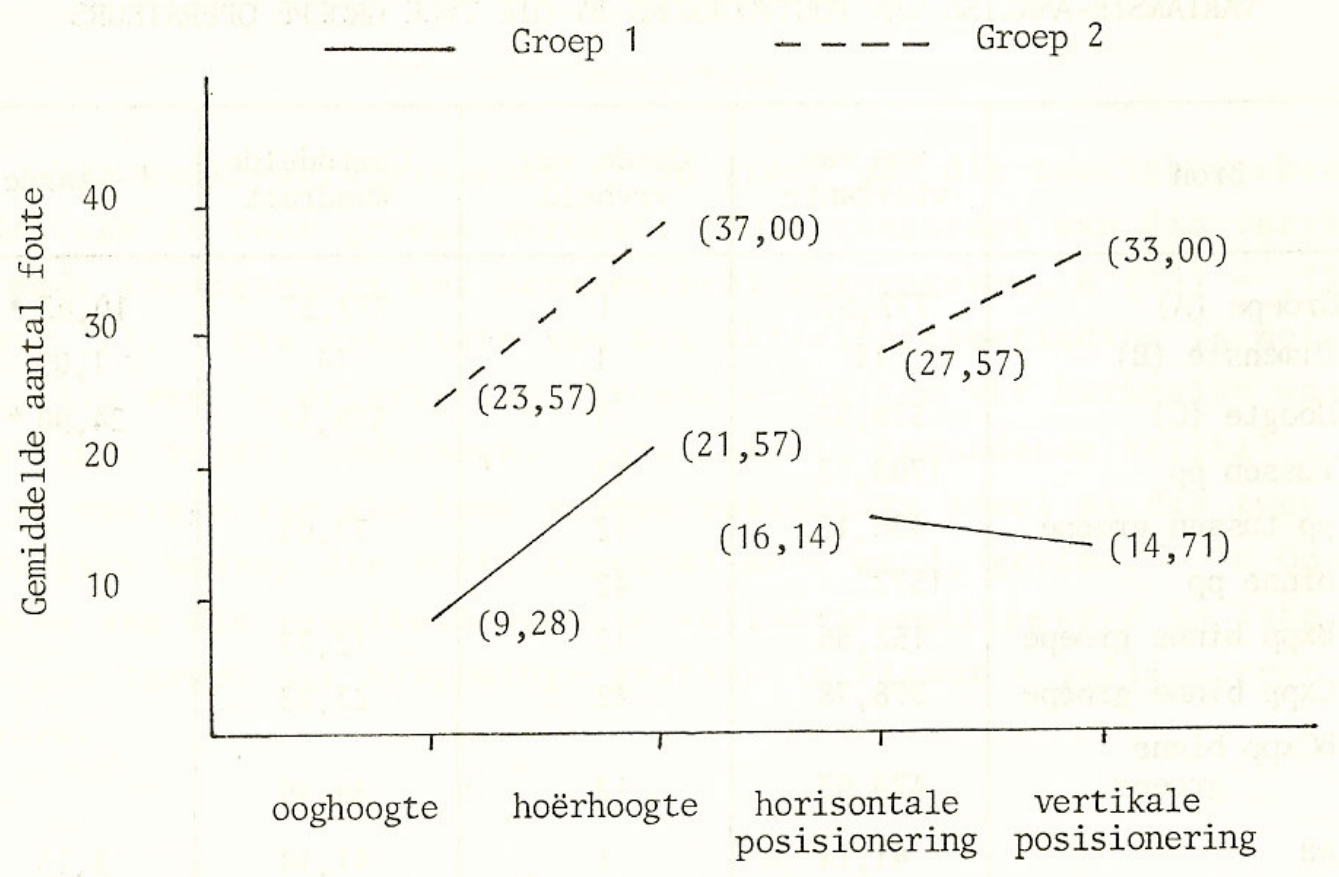

Figuur 1 Gemiddelde aantal foute per persoon in die twee groepe operateurs

Die mening van vurkhyseroperateurs aangaande die moeilikheidsgraad van die vurkhysertake word in Tabel 2 uiteengesit. In Tabel 2(a) word die gemiddelde rangorde waarin die operateurs die saamgestelde take geplaas het, aangedui. Tabel 2(b) toon die gemiddelde rangorde aan waarin die aktiwiteite wat met die opligtaak verband hou, geplaas is. Die operateurs het betekenisvol ooreengestem in hulle beoordelings van die moeilikheidsgraad van die saamgestelde take en die waarnemingsaktiwiteite soos afgelei kan word uit die konkordansie-koëffisiënte wat onderskeidelik $W(5)=, 34$, p <,001 en $W(3)=, 15, \mathrm{p}<, 001$ was. 
TABEL 2

RANGORDE VAN VURKHYSERTAKE IN TERME VAN MOEILIKHEIDSGRAAD

\begin{tabular}{|l|c|l|c|}
\hline \multicolumn{2}{|c|}{ (a) SAAMGESTELDE TAKE } & \multicolumn{2}{l|}{ (b)WAARNEMINGSAKTIWITEIT } \\
\hline Taak & Rang & Aktiwiteit & Rang \\
\hline Manipuleer vurkhyser & 1 & Verstelling van hellingshoek & 1 \\
Afpak & 2 & van vurkhysermas & Nadering tot vrag \\
Stapel & 3 & $\begin{array}{l}\text { Vertikale posisionering } \\
\text { van vurk }\end{array}$ & 3 \\
Aflaai (voertuie) & 4 & Horisontale & 4 \\
Laai (voertuie) & 5 & & \\
Bestuur met vrag & 6 & & \\
\hline
\end{tabular}

Die mening van die operateurs aangaande moontlike ontwerpveranderings aan die vurkhysers, word in Tabel 3 aangetoon . Tabel 3(a) toon die mening van operateurs ten opsigte van veranderinge aan bestaande vurkhyserapparaat, terwyl Tabel 3(b) hul menings met betrekking tot bykomstige apparaat weerspieël. Die mate van ooreenstemming tussen die operateurs is ook met behulp van 'n tweerigting variansie-analise ondersoek. 
$\underline{\text { TABEL } 3}$

DIE MENING VAN OPERATEURS IN TERME VAN GEMIDDELDE SKAALWAARDES AANGAANDE MOONTLIKE VERANDERINGE AAN VURKHYSERS

\begin{tabular}{|c|c|c|c|}
\hline \multicolumn{2}{|c|}{$\begin{array}{l}\text { (a) Wenslikheid van veranderinge } \\
\text { aan bestaande vurkhyserapparaat }\end{array}$} & \multicolumn{2}{|c|}{$\begin{array}{l}\text { (b) Wenslikheid met betrekking } \\
\text { tot bykomstige apparaat }\end{array}$} \\
\hline Apparaat & $\begin{array}{l}\text { Gemiddelde } \\
\text { skaalwaarde }\end{array}$ & Apparaat & $\begin{array}{l}\text { Gemiddelde } \\
\text { skaalwaarde }\end{array}$ \\
\hline $\begin{array}{l}\text { Verandering aan } \\
\text { stuurgrootte }\end{array}$ & 1 & $\begin{array}{l}\text { Byvoeg van outo- } \\
\text { matiese rem by } \\
\text { horisontale } \\
\text { posisionering }\end{array}$ & 2,5 \\
\hline $\begin{array}{l}\text { Verandering aan } \\
\text { posisie van hand- } \\
\text { kontroles }\end{array}$ & 1,1 & $\begin{array}{l}\text { Byvoeg van } \\
\text { diskrete opsie }\end{array}$ & \\
\hline $\begin{array}{l}\text { Verandering van } \\
\text { stuurhelling }\end{array}$ & 1,1 & $\begin{array}{l}\text { posisionering } \\
\text { van vurk }\end{array}$ & 3,5 \\
\hline $\begin{array}{l}\text { Verandering in } \\
\text { stuurspeling }\end{array}$ & 1,6 & $\begin{array}{l}\text { Byvoeg van } \\
\text { apparaat om } \\
\text { verspreiding van } \\
\text { vrag op vurke } \\
\text { aan te dui }\end{array}$ & 3,5 \\
\hline $\begin{array}{l}\text { Verandering aan } \\
\text { sitplekverstellings }\end{array}$ & 2,7 & & \\
\hline
\end{tabular}

Die resultate hiervan word in Tabel 4 opgesom terwyl die betroubaarheid van operateurs ten opsigte van die twee stelle menings bereken is as $r_{t t}=, 97$ en $r_{t t}=, 93$ respektiewelik.

\section{$\underline{\text { TABEL } 4}$}

\section{VARIANSIE-ANALISE VAN DIE OPERATEURSBEOORDELINGS}

(a) Variansie-analise van beoordelings ten opsigte van bestaande apparaat

\begin{tabular}{|l|c|c|c|c|}
\hline BRON & $\begin{array}{c}\text { SOM VAN } \\
\text { VIERKANTE }\end{array}$ & $\begin{array}{c}\text { GRADE VAN } \\
\text { VRYHEID }\end{array}$ & $\begin{array}{c}\text { GEMIDDELDE } \\
\text { KWADRAAT }\end{array}$ & $\begin{array}{c}\text { F- } \\
\text { WAARDE }\end{array}$ \\
\hline Veranderinge & 49,22 & 4 & 12,30 & $28,60 *$ \\
Operateurs & 12,37 & 23 & 0,53 & 1,23 \\
Fout & 40,38 & 92 & 0,43 & \\
\hline
\end{tabular}

$$
* \mathrm{p}<, 01
$$


(b) Variansie-analise van beoordelings ten opsigte van bykomstige apparaat

\begin{tabular}{|l|c|c|c|c|}
\hline BRON & $\begin{array}{c}\text { SOM VAN } \\
\text { VIERKANTE }\end{array}$ & $\begin{array}{c}\text { GRADE VAN } \\
\text { VRYHEID }\end{array}$ & $\begin{array}{c}\text { GEMIDDELDE } \\
\text { KWADRAAT }\end{array}$ & $\begin{array}{c}\text { F- } \\
\text { WAARDE }\end{array}$ \\
\hline Verandering & 15,36 & 2 & 7,68 & $13,47^{*}$ \\
Operateurs & 45,32 & 23 & 1,97 & 3,45 \\
Fout & 26,63 & 46 & 0,57 & \\
\hline
\end{tabular}

$* \mathrm{p}<, 01$

\section{BESPREKING}

Die resultate wat uit die studie verkry is suggereer dat die vermoë van operateurs om te voldoen aan die dieptewaarnemingseise wat deur die bestaande ontwerp van die vurkhyser gestel word, 'n belangrike faktor in die effektiewe hantering van vurkhysers is. In hierdie verband byvoorbeeld skyn foutvoorkoms by dieptewaarnemingsaktiwiteite betekenisvol tussen operateurs te onderskei. Dit geld vir die horisontale posisionering van die vurkhyser sowel as die vertikale posisionering van die vurke. Ten opsigte van die vertikale posisionering van die vurkhyser se vurke wil dit voorkom asof 'n groter visuele hoek 'n beduidende vermeerdering in die aantal foute van vurkhyseroperateurs tot gevolg het. In die verband dien daar op gewys te word dat hierdie bevinding nie strydig is met die van Drury, Cardwell en Easterby (1974) nie, maar dat dit die implikasies van die visuele hoek in 'n essensieel andersoortige vorm van dieptewaarneming illustreer. Die verskil tussen die visuele hoek in die "langsnee-stop" taak wat deur genoemde skrywers ondersoek is en die visuele hoek wat by die vertikale posisioneringstaak ter sprake is, word in Figuur 2 aangetoon.
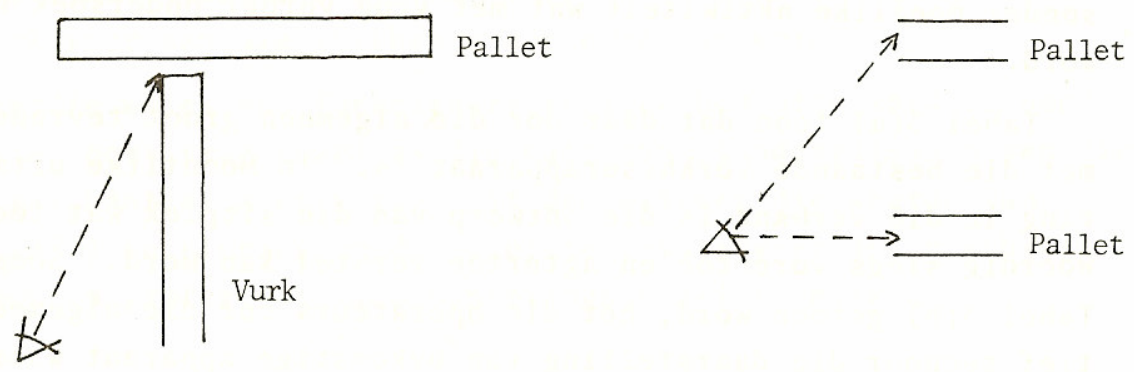

VISUELE HOEK BY LANGSNEE-STOP

Figuur 2 Verskil tussen visuele hoek implikasies by twee soorte dieptewaarnemingstake 
Addisionele bevestiging van die implikasies van dieptewaarneming op vurkhyserhantering kan uit die mening van operateurs aangaande taakmoeilikheid afgelei word. So byvoorbeeld dui die range wat aan die "gang-deurry taak" en "nadering tot die vrag" toegeken is daarop dat Drury \& Dawson (1974) en Drury, Cardwell \& Easterby (1974) inderdaad kritieke veranderlikes in die waarnemingstaak van die vurkhyseroperateur ondersoek het.

Die relatiewe hoë rang wat aan "afpak" toegeken is, kan waarskynlik daaraan toegeskryf word dat dié taak in teenstelling met die ander take in Tabel 2(a) by uitnemendheid die verskillende dieptewaarnemingseise wat met vurkhyserhantering verband hou, verteenwoordig. Die aktiwiteite waarin hierdie eise gemanifesteer word, word in Tabel 2(b) getoon. Volgens die tabel is die skatting van die helling van die vurkhysermas 'n besonder moeilike aktiwiteit wat met vrug verder ondersoek kan word.

Tabel 3(a) toon dat daar oor die algemeen groot tevredenheid met die bestaande vurkhyserapparaat is. ' $n$ Moontlike uitsondering in die verband is die ontwerp van die sitplek wat teenswoordig slegs vorentoe en agtertoe verstel kan word. Soos in Tabel 3(b) getoon word, het die operateurs oor die algemeen positief teenoor die daarstelling van bykomstige apparaat waardeur verligting aan die dieptewaarnemingseise gebring word, gereageer.

\section{GEVOLGTREKKING}

Uit die bevindinge van hierdie en ander studies blyk dit dat verskillende vorms van dieptewaarneming 'n belangrike rol in die effektiewe funksionering van die operateurvurkhyserstelsel speel. Dat die keuring en opleiding van operateurs in hierdie verband sekere implikasies inhou, spreek vanself. In die lig van die ergonomiese konsep van funksieverdeling, kan die aanname dat dieptewaarnemingsaktiwiteite deur die operateur uitgevoer moet word, egter bevraagteken word. In terme van die oordrag van hierdie aktiwiteite aan die vurkhyserkomponent, kan die afleiding uit die studie gemaak word dat

- $\quad$ die vertikale beweging van die vurkhyser se vurke op 'n diskrete sowel as die huidige kontinue basis kan plaasvind

- $\quad$ aanvullende ouditiewe terugvoering aan die operateur voorsien kan word wanneer die vurke en hysermas 'n verlange posisie bereik het

- $\quad$ ouditiewe inligting by 'n oneweredige verspreiding van vrag op die vurke beskikbaar gestel kan word en 
- die finale remaksie by die horisontale posisionering van die vurkhyser aan die vurkhyser oorgedra kan word.

Hierdie wyses van funksieherverdeling hou uiteraard verband met die soort vrag sowel as die mate van standaardisasie van die vrag wat hanteer moet word. Dit demonstreer die waarde van Fox (1971) se siening om die operateur-vurkhyser as 'n substelsel van 'n groter materiaalhanteringstelsel te beskou.

\section{OPSOMMING}

In die operateur-vurkhyserstelsel is die visuele waarnemingstaak in sy geheel aan die operateur toegeken. Die vermoë van operateurs om te voldoen aan die dieptewaarnemingseise wat deur die bestaande ontwerp van die vurkhyser gestel word, is in hierdie studie ondersoek. Uit die resultate van die studie blyk dit dat foutvoorkoms by dieptewaarnemingsaktiwiteite betekenisvol tussen operateurs onderskei en dat 'n groter visuele hoek 'n beduidende vermeerdering in die aantal foute by die vertikale posisionering van die vurke tot gevolg het. Die resultate van die studie word in terme van ontwerpimplikasies bespreek.

\section{VERWYSINGS}

Anoniem. Looking forward and backward. Mechanical handling, 1976, 22-24.

Drury, C.G., Cardwell, M.C. \& Easterby, R.S. Effects of depth perception on performance of simulated material handling tasks. Ergonimics, 1974, 17(15), 677-690.

Drury, C.G. \& Dawson, P. Human factors limitations in fork-lift truck performance. Ergonomics, 1974, 19(4), 447-456.

Fox, J.G. Human factors and fork lift trucks. International Handling Review, 1971, 1(1), 3-4. Singleton, W.T. Systems Design. In C. Brown \& N.T. Martin (reds) Human Aspects of Manmade Systems. The Open University Press, 1977. 